\title{
Nohut Üretiminde Enerji Kullanım Etkinliği ve Sera Gazı (GHG) Emisyonunun Belirlenmesi (Adana ili örneği)
}

\author{
Hasan Ali Karaağaç ${ }^{1}$, Mehmet Firat Baran ${ }^{2 *}$, Durdane Mart ${ }^{1}$, Ali Bolat ${ }^{1}$, Ömer Eren ${ }^{3}$ \\ ${ }^{1}$ Doğu Akdeniz Tarımsal Araştırma Enstitüsü Müdürlüğü, Adana, Türkiye (ORCIDS: 0000-0003-4847-0426; 0000-0002-2944-1227; 0000-0002-1019-0069;) \\ ${ }^{2}$ Siirt Üniversitesi Ziraat Fakültesi Biyosistem Mühendisliği Bölümü, Siirt, Türkiye (ORCID: 0000-0002-7657-1227) \\ ${ }^{3}$ Hatay Mustafa Kemal Üniversitesi Ziraat Fakültesi Biyosistem Mühendisliği Bölümü, Hatay, Türkiye (ORCID:0000-0001-6283-4367)
}

(İlk Geliş Tarihi 6 Şubat 2019 ve Kabul Tarihi 11 Mayıs 2019)

(DOI: $10.31590 /$ ejosat.523080)

ATIF/REFERENCE: Karaağaç, H.A, Baran M.F, Mart, D., Bolat, A., Eren, Ö. (2019). Nohut Üretiminde Enerji Kullanım Etkinliği ve Sera Gazı (GHG) Emisyonunun Belirlenmesi (Adana ili örneği). Avrupa Bilim ve Teknoloji Dergisi, (16), 41-50.

$\ddot{O} \mathbf{z}$

Bu çalışmada, 2017 yılında Adana koşullarında yetiştirilen nohut üretiminin enerji bilançosunun oluşturulması ve sera gazı (GHG) emisyonunun belirlenmesi amaçlanmıştır. Çalışmada kullanılan alet-makinelerin ekonomik ömürleri, iş başarısı, yakıt-yağ tüketimleri, makine ağırlıkları ile gübre, tohum miktarları gibi temel veriler, mevcuttaki yapılan ölçümlerden, yapılan diğer çalışmalardan, çeşitli kaynak ve kataloglardan temin edilmiştir. Yapılan değerlendirmeler sonucunda nohut üretiminde enerji çıktı/girdi oranı 1.82, özgül enerji değeri $9.99 \mathrm{MJ} \mathrm{kg}^{-1}$, enerji üretkenliği $0.10 \mathrm{kgMJ}^{-1}$, net enerji verimi $8319.86 \mathrm{MJ} \mathrm{ha}^{-1}$ olarak hesaplanmıştır. Nohut üretiminde toplam enerji girdileri içerisinde en yüksek kullanım oranı \% 35.59 ile yakıt-yağ enerjisinde olduğu bulunmuştur. Bunu sırasıyla \% 24.63 ile gübre enerjisi, \%23.49 ile tohum enerjisi, \% 8.43 ile makine enerjisi, \% 7.61 ile ilaç enerjisi ve $\% 0.24$ ile insan enerjisi takip etmiştir. Nohut üretimi için toplam GHG emisyonu $1638.85 \mathrm{kgCO}_{2 \text {-eşha }}{ }^{-1}$ olarak hesaplanmıştır. Toplam GHG emisyonları içerisinde en yüksek pay tohuma (\%60.52) aittir. Tohumu sırasıyla dizel yakıt tüketimi (\%17.56), azotlu gübre kullanımı (\%8.37), fosfatlı gübre kullanımı (\%4.32), makine kullanımı (\%3.69), fungusit kullanımı (\%2.62), herbisit kullanımı (\%2.47) ve insan işgücü (\%0.46) takip etmiştir. Buna ilave olarak, nohut üretiminde GHG oranı $1.62 \mathrm{kgCO}_{2 \text {-eș }} \mathrm{kg}^{-1}$ olarak hesaplanmıştır.

Anahtar Kelimeler: Adana, nohut, enerji etkinliği, sera gazı (GHG) emisyonu, GHG oranı

\section{Determination of Energy Usage Efficiency and Greenhouse Gas (GHG) Emissions in Chickpea Production (The case of Adana Province)}

\begin{abstract}
In this study, it has been aimed to form the energy balance and greenhouse gas (GHG) emissions in the production of chickpea (Cicer arietinum L.) in Adana Province. 2017. Main data used in this study, such as economical life, labor success, fuel-oil consumptions, machine weights of the tools and machines used in second crop chickpea and fertilizer, seed amounts have been obtained from the other studies, various sources and catalogues. As a result of the evaluations energy output/input rate was obtained as 1.82, the specific energy value was obtained 9.99, net energy production was obtained $8319.86 \mathrm{MJ} /$ ha in groundnut. For the chickpea, fuel-oil energy was the highest energy with $35.59 \%$ in total energy budget followed, fertilizer energy, seed energy, machinery energy, chemicals energy and human labour energy inputs with $24.63 \%, 23.49 \%, 8.43 \%, 7.61 \%$ and $0.24 \% \%$ respectively. Total GHG emission was calculated as $1638.85 \mathrm{kgCO}_{2 \text {-eq }} \mathrm{ha}^{-1}$ for chickpea production with the greatest portions for seed $(60.52 \%)$. The seed followed up diesel fuel consumption $(17.56 \%)$, nitrogen manure usage $(8.37 \%)$, phospate manure usage $(4.32 \%)$, machine usage $(3.69 \%)$, fungusit usage $(2.62 \%)$, herbisit usage $(2.47 \%)$ and human labour $(0.46 \%)$ respectively. Additionally, $\mathrm{GHG}$ ratio value was calculated as $1.62 \mathrm{kgCO}{ }_{2-}$ eq $\mathrm{kg}^{-1}$ in chickpea production.
\end{abstract}

Keywords: Adana, chickpea, energy efficiency, greenhouse gas (GHG) emissions, GHG ratio

* Sorumlu Yazar: Siirt Üniversitesi, Ziraat Fakültesi, Biyosistem Mühendisliği Bölümü, Siirt, Türkiye, ORCID: 0000-0002-7657-1227, mfb197272@gmail.com 


\section{Giriş}

Ülkemizde yemeklik tane baklagiller arasında nohut, toplam ekim alanlarının \% 52.5'ini ve toplam yemeklik tane baklagil üretiminin ise \% 44'ünü oluşturmaktadır. Aynı zamanda nohut, ülkemizde hem ekim alanı hem de üretim miktarı açısından yemeklik baklagiller arasında ilk sırada yer almaktadır (Küçükalbay ve Akbolat, 2015).

Baklagiller içerisinde önemli bir yeri olan nohut, ilk çağlardan beri kültürü yapılarak insanlar tarafından tüketilen ve insan beslenmesinde büyük önem taşıyan bir tarım ürünüdür (Güler, 2011; Kılıç, 1997).

Nohut, toprak isteği bakımından kanaatkâr oluşu dolayısıyla ve köklerinin havanın serbest azotunu tespit etmesi bakımından hububat-yemeklik münavebesinde önemi çok büyüktür. Nohut, danelerinde bulunan \% 20-25 protein, \% 40-60 karbonhidrat, \% $4.5-5.5$ yağ, fosfor ve kalsiyum sayesinde insan beslenmesinde önemli bir yere sahiptir (Anonim, 2018a).

Bir baklagil bitkisi olması ve köklerindeki nodüllerde havanın serbest azotunu bağlayabilmesi nedeniyle iyi bir münavebe bitkisi olarak önemli olan nohut, kendisinden sonra ekilecek bitkiye azot ve organik maddece zengin bir toprak bırakmaktadır (Anonim, 2018b). Adana'da nohut, kışlık ve yazlık olmak üzere 2 dönemde ekilir. Rakımı 750 m yüksekliğinden daha az olan yerlerde kışlık ekimler, 750 m yükssekliğinden daha fazla olan yerlerde yazlık ekimler yapılır. Kışlık ekimler aralık ayı içinde, yazlık ekimler ise şubat, mart ayında yapılmaktadır. Adana'da üretimi yapılan nohudun ekim alanı, üretim miktarları ve verim değerleri Tablo 1'de verilmiştir.

Tablo 1. Yıllar itibarı ile Adana ve Türkiye nohut üretim miktarları (TÜIK 2018)

\begin{tabular}{ccccccc}
\hline \multirow{3}{*}{ Y1lar } & \multicolumn{3}{c}{ Adana } & \multicolumn{3}{c}{ Türkiye } \\
\cline { 2 - 7 } & $\begin{array}{c}\text { Alan } \\
(\mathrm{da})\end{array}$ & $\begin{array}{c}\text { Uretim } \\
(\text { Ton })\end{array}$ & $\begin{array}{c}\text { Verim } \\
(\mathrm{kg} / \mathrm{da})\end{array}$ & $\begin{array}{c}\text { Alan } \\
(\mathrm{da})\end{array}$ & $\begin{array}{c}\text { Üretim } \\
(\text { Ton })\end{array}$ & $\begin{array}{c}\text { Verim } \\
(\mathrm{kg} / \mathrm{da})\end{array}$ \\
\hline 2013 & 71.782 & 7.392 & 103 & 4.188 .187 & 506.000 & 121 \\
2014 & 65.585 & 6.876 & 105 & 3.881 .693 & 450.000 & 116 \\
2015 & 55.655 & 6.098 & 110 & 3.572 .220 & 460.000 & 129 \\
2016 & 50.755 & 5.800 & 114 & 3.516 .872 & 455.000 & 129 \\
2017 & 50.531 & 5.096 & 101 & 3.926 .726 & 470.000 & 120 \\
\hline
\end{tabular}

Tarımsal üretimle ilgili olarak yapılacak enerji analizleri tarımsal sistemlerin enerji tüketimi açısından tanımlanıp gruplandırılmasında önemli bir yaklaşımdır. Üretiminde verimi artırmak ve girdileri azaltmak için üretimde kullanılan girdi ve çıktıların dikkatli bir şekilde analiz edilmesi gereklidir (Sabah, 2010).

Bununla birlikte, daha yoğun enerji kullanımı, insan sağlığını etkileyen ve sera gazı (GHG) emisyonları gibi önemli çevre sorunlarını ortaya çıkarmaktadır, bu nedenle girdilerin verimli kullanımı, sürdürülebilir tarımsal üretim açısından önemli hale gelmektedir. Tarımsal üretimde sera gazı emisyonları makine kullanımı, dizel yakıt tüketimi, kimyasal gübre kullanımı ve elektrik tüketimi sebebiyle ortaya çıkmakta ve doğal olarak enerji girdisinin artmasıyla da sera gazı emisyonları da artmaktadır.

Enerji etkinliği değerini artırmak için ya verimin artırılması ya da girdilerin azaltılması gerekmektedir. Özellikle toplam enerji girdisi içerisinde büyük yer tutan yakıt, kimyasal gübreler, tarımsal ilaçlar, makine ve traktör girdilerinin azaltılması gerekmektedir. Verimin artırılması belirli sınırlar içerisinde sağlanabilir. Fakat enerji kullanım etkinlik değeri girdilerin bilinçli bir şekilde yapılmasıyla (ilaçlama, mekanizasyon ve gübreleme) azaltılabilir (Çelen, 2016).

Enerji kullanım etkinliğini belirlemek amacıyla yapılan bazı çalışmalarda; nohut, (Yaldız v.dğr., 1990; Marakoğlu v.dğr., 2010), misır (Kökten v.dğr., 2018), mısır (Öztürk ve Küçükerdem, 2016), lavanta (Gökdoğan, 2016), arpa (Baran ve Gökdoğan, 2014), ikinci ürün silajlık mısır (Baran v.dğr., 2016), şekerpancarı (Baran ve Gökdoğan, 2016), ikinci ürün ayçiçeği (Bayhan, 2016), buğday ve ayçiçeği (Unakıtan ve Aydın, 2016), buğday (Demir, 2018), mısır (Abbas v.dğr., 2018) ürünlerin üretiminde enerji kullanım etkinlikleri belirlenmiştir. Bunun yanında GHG emisyonlarını belirlemek amacıyla yapılan çalışmalarda da; arpa (Mohammadi v.dğr., 2014; Eren v.dğr., 2019), nohut (Elhami v.dğr., 2016; Eren v.dğr., 2019), silajl1k misır (Mohammadi v.dğr., 2014; Eren v.dğr., 2019), pamuk (Pishgar-Komleh v.dğr., 2012; Eren v.dğr., 2019), pirinç (Wang v.dğr., 2010; Eren v.dğr., 2019); şeker pancarı (Yousefi v.dğr., 2014; Eren v.dğr., 2019), ayçiçeği (Spugnoli v.dğr., 2012; Eren v.dğr., 2019) buğday (Mohammadi v.dğr., 2014) ürünlerinin üretiminde GHG emisyonlarını belirlemişlerdir. Bu çalışmada Adana'da 2017 yılının nohut üretiminin enerji kullanım etkinliği ve GHG emisyonu ortaya konulmaya çalışılmıştır. 


\section{Materyal ve Metot}

\section{1. Çalışma alanı}

Akdeniz iklimi görülen Adana ilinde uzun yıllar yılık yă̆ı̧s miktarı ortalama $644.6 \mathrm{~mm}$, ortalama sıcaklık ise yaklaşık $19.1{ }^{\circ} \mathrm{C}$ civarındadır (MGM, 2018). Çalışmada nohut üretiminde kullanılan çeşitli girdi miktarları ve elde edilen çıktı miktarları değerleri değiş̧ik kaynaklardan (Türkiye İstatistik Kurumu, daha önce konuyla ilgili veya benzer çalışmalardan), tarım alet ve makinaların teknik verileri ise bölgedeki uygulamalardan ve kataloglardan alınmıştır. Adana'da nohut üretimi için yapılan kültürel uygulamalar ve bakım işlemleri Tablo 2'de belirtilmiştir.

Tablo 2. Nohut Üretimi Iç̧in Kültürel Uygulamalar ve Bakım Işslemleri

\begin{tabular}{|c|c|}
\hline Kültürel Uygulamalar & Uygulamanın Özelliği \\
\hline Toprak işleme & $\begin{array}{l}\text { Toprak, yaz veya sonbahar mevsiminde pulluk ile } 20-25 \mathrm{~cm} \text { derinlikte sürülür. } \\
\text { Goble ile bir kez veya gerekirse } 2 \text { kez toprak tekrar işlenir, arkasından tapan ile } \\
\text { toprak düzeltilir. }\end{array}$ \\
\hline Ekim & $\begin{array}{l}\text { Nohut ekiminde en uygunu mibzerle ekimdir. Mibzerle ekimde ekim normu, } \\
\text { tane iriliğine göre değişmekle birlikte, dekara } 10-13 \mathrm{~kg} \text { tohum olabilmektedir } \\
\text { (Mart, 2018). Pnömatik ekim makinası ile sıra arası } 70 \mathrm{~cm} \text {, sıra üzeri ortalama } \\
5-8 \mathrm{~cm} \text {, ekim derinliği ortalama } 5 \mathrm{~cm} \text { olacak şekilde ekim yapılır. }\end{array}$ \\
\hline Gübreleme & $\begin{array}{l}\text { Baklagillerde bitkinin ilk gelişme döneminde, köklerde nodoziteler oluşana } \\
\text { kadar ekimle birlikte dekara 2-3 kg saf azot ve } 5-6 \mathrm{~kg} \mathrm{P}_{2} \mathrm{O}_{5} \text { önerilmektedir } \\
\text { (Mart, 2018). Gübre, ekim öncesi toprak işleme sırasında gübre dăğtma } \\
\text { makinası ile veya ekimle beraber toprağa verilir }\end{array}$ \\
\hline Ara çapa & Nohut yetiştirilmesi süresince toplam 1 defa traktör ara çapa ile çapalanabilir. \\
\hline Yabancı Ot Mücadelesi & $\begin{array}{l}\text { Genellikle ekim sonrası çıkış öncesi veya çıkış sonrası olmak üzere } 1 \text { uygulama } \\
\text { şeklinde olmaktadır. }\end{array}$ \\
\hline Zirai Mücadele & $\begin{array}{l}\text { Nohut üretiminde çiçeklenme öncesi ve çiçeklenme sonrası olmak üzere } 2 \mathrm{kez} \\
\text { fungusit uygulaması yapılmaktadır. }\end{array}$ \\
\hline Hasat & $\begin{array}{l}\text { Nohutta yaprak, dal ve baklalar kahverengine döndüğünde ve dane nemi \% } \\
11 \text { 'in altına düştüğünde biçerdöverle hasat edilmektedir. }\end{array}$ \\
\hline
\end{tabular}

\section{2 Çalışmada Kullanılan Girdiler}

Ekim normu sıra üstü arasına ve tohum büyüklüğüne bağlı olarak $10-13 \mathrm{~kg} \mathrm{da}^{-1}$ arasında değişmekte olup, bu çalışmada ekim normu $13 \mathrm{~kg} / \mathrm{da}$ olarak, kullanılan gübre miktarı $6 \mathrm{~kg} \mathrm{da}^{-1}$ saf fosfor ve $3 \mathrm{~kg} \mathrm{da}^{-1}$ saf azot olarak alınmıştır (Mart, 2018). Yabancı ot mücadelesi için çıkış öncesi veya sonrası olmak üzere 1 herbisit uygulaması, çeşitli hastalık için 2 defa fungusit uygulaması hesaplanmıştır. Adana'da nohut üretiminin enerji etkinliğinin hesaplanabilmesi için öncelikle enerji girdilerinin ve enerji çıktılarının hesaplanması gerekir.

Enerji girdileri insan gücü enerjisi, makine enerjisi, yakıt-yağ enerjisi, tohum enerjisi, su enerjisi, gübre enerjisi ve ilaç enerjisinden oluşmaktadır. Enerji girdisinin belirlenmesinde Farrel v.dğr (2006)'dan uyarlanan aşağıdaki eşitlikten faydalanılmıştır:

$T E G=\sum_{i=1}^{n} R(i) \times E_{e s ̦}(i)$

Burada;

TEG : Tarımsal enerji girdisi $\left(\mathrm{MJ} \mathrm{ha}^{-1}\right)$,

R(i) : i girdisinin uygulama miktarı $\left(\right.$ birim $_{\text {girdi }} \mathrm{ha}^{-1}$ ),

$\mathrm{E}_{\mathrm{eş}}(\mathrm{i}) \quad$ : i girdisinin enerji eşdeğeri $\left(\mathrm{MJ}\right.$ birim $\left._{\text {girdi }}{ }^{-1}\right)$ dir.

Enerji çıktısı ise birim alandan elde edilen ürün ve yan üründen oluşmaktadır. Enerji çıktısının belirlenmesinde uyarlanan aşağıdaki eşitlikten faydalanılmıştır: 
$T E C ̧=Y * L H V$

Burada;

TEÇ : Tarımsal enerji çıktısı $\left(\mathrm{MJ} \mathrm{ha}^{-1}\right)$,

Y $\quad$ Verim $\left(\mathrm{kg} \mathrm{ha}^{-1}\right)$

LHV : Alt 1sıl değer $\left(\mathrm{MJ} \mathrm{kg}^{-1}\right)^{\prime}$ dir.

Tarımsal girdilerin ve çıktıların enerji eşdeğeri katsayıları Tablo 3'de verilmiştir.

Tablo 3. Tarımsal üretimde girdi ve çıktıların enerji eşdeğerleri

\begin{tabular}{|c|c|c|}
\hline Girdiler & $\begin{array}{c}\text { Enerji Eşdeğeri } \\
\text { Katsayısı (MJ birim }^{-1} \text { ) }\end{array}$ & Referanslar \\
\hline İnsan İşgücü $(h)$ & 1.96 & $\begin{array}{l}\text { Davoodi ve Houshyar, 2009; } \\
\text { Mousavi Avval v.dğr., 2011; } \\
\text { Baran v.dğr., } 2016\end{array}$ \\
\hline \multicolumn{3}{|c|}{ Makine Üretim Enerjisi (kg) } \\
\hline Traktör & 158.30 & Barut v.dğr., 2011 \\
\hline Toprak İşleme Aletleri & 121.30 & Barut v.dğr., 2011 \\
\hline \multicolumn{3}{|l|}{ Yakıt $(L)$} \\
\hline Dizel & 35.69 & Sabah, 2010; Arıkan, 2011; Eren, 2011 \\
\hline Yağ & 6.51 & Sabah, 2010; Arıkan, 2011; Eren, 2011 \\
\hline \multicolumn{3}{|l|}{ Kimyasal Gübreler $(\mathrm{kg})$} \\
\hline Azot $(\mathrm{N})$ & 60.60 & Öztürk, 2011; Barut v.dğr. 2011; Bayhan, 2016 \\
\hline Fosfor $\left(\mathrm{P}_{2} \mathrm{O}_{5}\right)$ & 11.10 & Öztürk, 2011; Barut v.dğr. 2011; Bayhan, 2016 \\
\hline \multicolumn{3}{|l|}{ İlaç (kg) } \\
\hline Herbisit & 269.00 & $\begin{array}{l}\text { Ferrago, 2003; Sabah, 2010; Arıkan, 2011; Eren, } \\
2011\end{array}$ \\
\hline Fungusit & 99.00 & Strapatsa v.dğr., 2006 \\
\hline \multicolumn{3}{|l|}{ Tohum (kg) } \\
\hline Nohut & 18.224 & Baran ve Gökdoğan, 2017 \\
\hline \multicolumn{3}{|l|}{ Çıktı } \\
\hline Nohut & 18.224 & Baran ve Gökdoğan, 2017 \\
\hline
\end{tabular}

Nohut üretiminde enerji kullanım etkinliğini belirleyebilmek amacıyla, Yılmaz v.dğr. (2010)'dan uyarlanan aşağıdaki 3, 4, 5 ve 6 numaralı formüller kullanılmıştır.

Enerji oran $=\frac{\text { TEÇ }}{\text { TEG }}$

Özgül enerji $\left(\mathrm{MJ} k g^{-1}\right)=\frac{\mathrm{TEG}}{\mathrm{Y}}$

Enerji üretkenliği $\left(\mathrm{kg} M J^{-1}\right)=\frac{\mathrm{Y}}{\mathrm{TEG}}$

Net enerji verimi $\left(\mathrm{MJ} h a^{-1}\right)=$ TEÇ - TEG

GHG emisyonunun belirlenmesinde Hughes v.dğr. (2011)'den uyarlanmış olan aşağıdaki eştlikten faydalanılmıştır:

$$
G H G_{h a}=\sum_{i=1}^{n} R(i) x E F(i)
$$

Burada;

$\mathrm{GHG}_{\mathrm{h}}$ : Sera gazı emisyonu $\left(\mathrm{kgCO}_{2-\mathrm{eş}} \mathrm{ha}^{-1}\right)$, 
R(i) : i girdisinin uygulama miktarı $\left(\right.$ birim $\left._{\text {girdi }} \mathrm{ha}^{-1}\right)$,

EF(i) : i girdisinin GHG emisyon eşdeğeri $\left(\mathrm{kgCO}_{2 \text {-eş }}\right.$ birim girdi $\left.^{-1}\right)$ dır.

Tarımsal girdilerin GHG emisyon katsayıları Tablo 4'de verilmiştir.

Tablo 4. Tarımsal üretimde ki girdilerin GHG emisyon eşdeğerleri

\begin{tabular}{|c|c|c|c|}
\hline Girdiler & Birim & $\begin{array}{c}\text { GHG emisyon eşdeğerleri } \\
\left(\mathrm{kgCO}_{2 \text {-es }} \text { Birim }^{-1}\right)\end{array}$ & Referanslar \\
\hline İnsan İşgücü & $\mathrm{h}$ & 0.700 & Nguyen ve Hermansen, 2012 \\
\hline Makine & MJ & 0.071 & Pishgar-Komleh v.dğr., 2012 \\
\hline Dizel yakıt & $\mathrm{L}$ & 2.760 & Clark v.dğr, 2016 \\
\hline $\operatorname{Azot}(\mathrm{N})$ & $\mathrm{kg}$ & 4.570 & BioGrace-II, 2015 \\
\hline Fosfor $\left(\mathrm{P}_{2} \mathrm{O}_{5}\right)$ & $\mathrm{kg}$ & 1.180 & BioGrace-II, 2015 \\
\hline Herbisit & $\mathrm{kg}$ & 23.100 & Maraseni v.dğr., 2010 \\
\hline Fungusit & $\mathrm{kg}$ & 14.300 & Maraseni v.dğr., 2010 \\
\hline Tohum & $\mathrm{kg}$ & 7.630 & Clark v.dğr., 2016 \\
\hline
\end{tabular}

GHG oranı, birim kg verim başına düşen GHG emisyon miktarı olarak tanımlanan bir indekstir. Houshyar v.dğr. (2015) ve Khoshnevisan v.dğr. (2014)'dan uyarlanmış olan aşağıdaki eşitlikle hesaplanmıştır:

$I_{G H G}=\frac{G H G_{h a}}{Y}$

Burada; $\mathrm{I}_{\mathrm{GHG}}$ : GHG oranı $\left(\mathrm{kgCO}_{2 \text {-es }} \mathrm{kg}^{-1}\right)$ ve $\mathrm{Y}$ : Verim $\left(\mathrm{kg} \mathrm{ha}^{-1}\right)^{\prime}$ dir.

Ayrıca nohut üretimindeki enerji girdileri, doğrudan ve dolaylı enerji girdileri olarak iki grupta hesaplanmıştır. Nohut üretiminde tarım alet ve makinaları tarafından tüketilen yakıt ve yağ enerji değeri doğrudan enerji girdisi olarak, kullanılan insan işgücü, tarım alet ve makinaları, gübre, ilaç ve tohumluk için tüketilen enerji değerleri dolaylı enerji girdisi olarak dikkate alınmıştır (Koçtürk ve Engindeniz, 2009). 2017 yılı için Adana'da nohut ekim alanı 50531 da, üretim miktarı 50096 ton ve verim ortalaması $101 \mathrm{~kg}^{-1} \mathrm{olarak}^{-1}$ gerçekleşmiştir (TÜİK, 2018).

\section{Araştırma Sonuçları ve Tartışma}

\subsection{Enerji Kullanım Etkinliği}

Adana'da nohut üretiminde enerji bilançosu Tablo 5'te ve nohut yetiştiriciliğinde enerji kullanım etkinliği değerleri Tablo 6'da verilmiştir. Tablo 5'e baktığımızda birim alan başına $24.67 \mathrm{MJ} \mathrm{ha}^{-1}$ insan enerjisi tüketilmiş, bu değerin toplam enerji girdisine oranı \% 0.24 ile en düşük girdiyi oluşturmuştur. Nohut üretiminde alet/makine enerjisinde 1 ha alan için $850.64 \mathrm{MJ}$ enerji tüketilmiş, bu değer

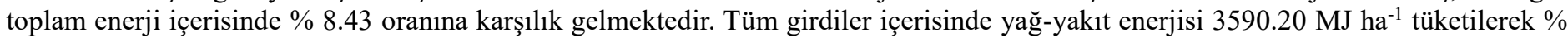
35.59 oranı ile en yüksek sırada bulunmuştur. Gübre enerji girdisi $2484.00 \mathrm{MJ}^{-1}$ ile \% 24.63 oranına karşılık gelmiştir. Nohut

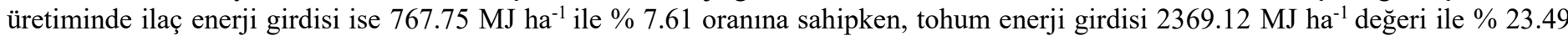
oranına sahip olmuştur. Nohut üretiminde tarımsal enerji girdisi $10086.38 \mathrm{MJ}^{-1}$ ve tarımsal enerji çıktısı $18406.24 \mathrm{MJ}^{-1} \mathrm{olarak}^{-1}$ saptanmiştır.

Tablo 6'yı incelediğimizde Adana'da nohut üretiminde enerji oranı 1.82 olarak hesaplanmıştır. Yapılan bu çalışmada saptanan enerji oranı 1.82 iken, Yaldız v.dğr. (1993) nohut üretiminde enerji oranını 3.33, Marakoğlu v.dğr. (2010) nohut üretiminde enerji oranını 0.20, Baran ve Gökdoğan (2017) Adıyaman'da nohut üretimindeki enerji oranını 2.58, Mandal v.dğr. (2002) Hindistan'da yapmış oldukları çalışmada nohutun enerji oranını 2.04 olarak tespit etmişlerdir. Adana koşullarında nohut üretiminde enerji üretkenliği, sadece birim üretim alanından (ha) alınan tohum miktarı dikkate alındığında $0.10 \mathrm{~kg} \mathrm{MJ}^{-1}$ olarak belirlenmiştir. Adana koşullarında nohut üretiminde, $1 \mathrm{MJ}$ enerji tüketimi karşılı̆̆ında $0.10 \mathrm{~kg}$ nohut tohumu üretilmektedir. Üretim sonucunda kazanılan toplam enerji miktarı ile üretim işlemlerinde kullanılan toplam enerji miktarı arasındaki fark net enerji verimi ( $\mathrm{MJ} \mathrm{ha}^{-1}$ ) olarak tanımlanır (Baran v.dğr. 2016). Adana koşullarında nohut üretiminde net enerji verimi, sadece birim üretim alanından (ha) alınan tohum miktarı dikkate alındı ğında 8319.86 $\mathrm{MJ} \mathrm{ha}^{-1}$ olarak hesaplanmıştır. Nohut üretiminde bu değer; Baran ve Gökdoğan (2017) Adıyaman ilinde yapmış oldukları çalışmalarında 19301.83 $\mathrm{MJ} \mathrm{ha}^{-1}$, Mandal v.dğr. (2002) Hindistan’da yaptıkları nohut üretiminde net enerji verimi değerini $33919 \mathrm{MJ}$ ha $^{-1}$ olarak tespit etmişlerdir. 
Tablo 5. Adana'da Nohut Üretiminde Enerji Bilançosu

\begin{tabular}{|c|c|c|c|}
\hline Girdiler ve Çıktılar & $\begin{array}{c}\text { Hektar Başına } \\
\text { Miktar }\end{array}$ & $\begin{array}{c}\text { Toplam Enerji } \\
\text { Girdisi (MJ ha }^{-1} \text { ) } \\
\end{array}$ & $\begin{array}{c}\text { Toplam Enerji Girdisine } \\
\text { Oranı (\%) } \\
\end{array}$ \\
\hline İnsan İşgücü (h) & 10.82 & 24.67 & 0.24 \\
\hline Toprak Hazırlama İşlemleri & 4.95 & 11.28 & \\
\hline Ekim ve Diğer İşlemler & 4.54 & 10.35 & \\
\hline Hasat & 1.33 & 3.04 & \\
\hline Makine (h) & 15.64 & 850.64 & 8.43 \\
\hline Traktör & 7.24 & 179.39 & \\
\hline Toprak Hazırlama İş̧lemleri & 4.95 & 87.87 & \\
\hline Ekim ve Diğer İşlemler & 2.79 & 143.66 & \\
\hline Hasat & 0.67 & 439.72 & \\
\hline Yakıt + Ya $\breve{g}(L)$ & 104.26 & 3590.20 & 35.59 \\
\hline Toprak Hazırlama İşlemleri & 64.79 & 2230.94 & \\
\hline Ekim ve Diğer İşlemler & 23.80 & 819.51 & \\
\hline Hasat & 15.68 & 539.74 & \\
\hline Kimyasal Gübreler (kg) & 90.00 & 2484.00 & 24.63 \\
\hline Fosfor $(\mathrm{P})$ & 60.00 & 666.00 & \\
\hline Azot $(\mathrm{N})$ & 30.00 & 1818.00 & \\
\hline Kimyasallar (kg) & 4.75 & 767.75 & 7.61 \\
\hline Herbisit & 1.75 & 470.75 & \\
\hline Fungusit & 3.00 & 297.00 & \\
\hline Tohum (kg) & 130.00 & 2369.12 & 23.49 \\
\hline Tarımsal Enerii Girdisi (MJ ha-1) & & $\underline{10086.38}$ & 100.00 \\
\hline Verim (kg) & 1010.00 & 18406.24 & \\
\hline Tarımsal Enerii Clktısı $\left(M^{\prime} h^{-1}\right)$ & & $\underline{18406.24}$ & \\
\hline
\end{tabular}

Tablo 6. Nohut yetişstiriciliğinde enerji kullanım etkinliği değerleri

\begin{tabular}{lcr}
\hline Enerji Kullanım Etkinliği & Birim & Değerler \\
\hline Enerji Oranı & - & 1.82 \\
Özgül Enerji & $\mathrm{MJ} \mathrm{kg}^{-1}$ & 9.99 \\
Enerji Üretkenliği & $\mathrm{kg} \mathrm{MJ}^{-1}$ & 0.10 \\
Net Enerji Verimi & $\mathrm{MJ} \mathrm{ha}^{-1}$ & 8319.86 \\
\hline
\end{tabular}

Tablo 7. Nohut yetiştiriciliğinde doğrudan, dolayl, yenilenebilir ve yenilenemez enerji girdileri

\begin{tabular}{|c|c|c|}
\hline & Enerji girdisi $\left(\mathrm{MJ} \mathrm{ha}^{-1}\right)$ & Oran (\%) \\
\hline Doğrudan enerji ${ }^{a}$ & 3614.87 & 35.83 \\
\hline Dolaylı enerji ${ }^{b}$ & 6471.51 & 64.17 \\
\hline Toplam & 10086.38 & 100.00 \\
\hline Yenilenebilir enerji $^{c}$ & 2393.79 & 23.73 \\
\hline Yenilenemez enerij $\mathrm{d}$ & 7692.59 & 76.27 \\
\hline Toplam & 10086.38 & 100.00 \\
\hline
\end{tabular}




\subsection{Sera Gazı (GHG) Emisyonu}

Nohut üretiminin GHG emisyonlarının sonuçları, Tablo 8'de verilmiştir. Toplam GHG emisyonları $1638.85 \mathrm{kgCO}_{2 \text {-eş }} \mathrm{ha}^{-1}$ olarak hesaplanmıştır. Toplam GHG emisyonları girdilerinin içerisinde en yüksek payı, \% 60.52'lik bir pay ile tohum girdisi almıștır. Bunu sırasıyla dizel yakıt girdisi (\% 17.56) ve kimyasal gübre girdileri (\% 12.69) takip etmiştir. GHG oranı ( $\mathrm{kg}$ verim başına) $1.62 \mathrm{kgCO}_{2 \text {-es }}$ $\mathrm{kg}^{-1}$ olarak belirlenmiştir. Benzer çalışmalarda, Eren v.dğr (2019) toplam GHG emisyonunu $2075 \mathrm{kgCO}_{2 \text {-es }}$ ha $^{-1}$ ve GHG oranını 1.16 $\mathrm{kgCO}_{2 \text {-es }} \mathrm{kg}^{-1}$ olarak, Elhami v.dğr. (2016)'da toplam GHG emisyonunu $6884.14 \mathrm{kgCO}_{2 \text {-eş }} \mathrm{ha}^{-1}$ ve $\mathrm{GHG}$ oranın $3.03 \mathrm{kgCO}_{2 \text {-eş }} \mathrm{kg}^{-1}$ hesaplamışlardır.

Table 8. Nohut üretiminde toplam GHG emisyonlart

\begin{tabular}{|c|c|c|c|c|}
\hline Girdiler & Birim & $\begin{array}{l}\text { Hektar başına miktar } \\
\text { (birim ha-1) }\end{array}$ & 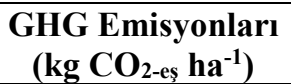 & $\begin{array}{l}\text { Pay } \\
(\%)\end{array}$ \\
\hline İnsan İşgücü & $\mathrm{h}$ & 10.82 & 7.57 & 0.46 \\
\hline Makine & MJ & 850.64 & 60.40 & 3.69 \\
\hline Dizel Yakıt & 1 & 104.26 & 287.76 & 17.56 \\
\hline Azot $(\mathrm{N})$ & $\mathrm{kg}$ & 30.00 & 137.10 & 8.37 \\
\hline Fosfor $\left(\mathrm{P}_{2} \mathrm{O}_{5}\right)$ & $\mathrm{kg}$ & 60.00 & 70.80 & 4.32 \\
\hline Herbisit & $\mathrm{kg}$ & 1.75 & 40.43 & 2.47 \\
\hline Fungusit & $\mathrm{kg}$ & 3.00 & 42.90 & 2.62 \\
\hline Tohum & $\mathrm{kg}$ & 130.00 & 991.90 & 60.52 \\
\hline TOPLAM & - & - & 1638.85 & 100.00 \\
\hline GHG Oranı (kg başına) & - & - & 1.62 & - \\
\hline
\end{tabular}

\section{Sonuç}

$\mathrm{Bu}$ araştırmada, Adana ilinde 2017 yılı üretim sezonunda nohut üretiminde enerji kullanım etkinliği ve GHG emisyonu yapılmıştır. Nohut üretimi yapan işletmelerde enerji oranı 1.82 olarak bulunmuştur. Hesaplamalar sonucunda, üretim girdileri içerisinde en yüksek payı yakıt-yağ enerjisinin aldığı, bunu sırasıyla gübre, tohum, makine, ilaç ve insan iş gücü enerjilerinin izlediği görülmektedir. Toplam GHG emisyonu $1638.85 \mathrm{kgCO}_{2 \text {-ȩ̣ }} \mathrm{ha}^{-1}$ ve $\mathrm{GHG}$ oranıda $1.62 \mathrm{kgCO}_{2 \text {-es }} \mathrm{kg}^{-1}$ olarak hesaplanmıştır. Yakıt-yağ girdisinde en fazla enerji tüketimi toprak işlemede görülmektedir. Ayrıca enerji tüketiminde ikinci en yüksek sırayı gübre enerjisinin aldığı görülmektedir. Bu nedenle nohut üretiminde yakıt-yağ girdisini ve gübre enerjisini azaltmak için farklı ve alternatif toprak işleme yöntemleri ile gübreleme yöntemlerinin araştırılması gerektiği düşünülmektedir. 


\section{Kaynakça}

Abbas,A., Yang, M, Yousaf,K., Khan, K.A, Iqbal T., Hassan S.G, , 2018. Comperative Analysis of Energy Use Efficiency in Food Grain Production Systems of Pakistan, Fresenius Environmental Bulletin, 27(2):1053-1059

Anonim,2018a. http://www.gencziraat.com/Tarla-Bitkileri/Nohut-Yetistiriciligi.html. Adresinden alınd1, Erişim Tarihi: 02.10 .2018

Anonim, 2018b. http://hayrabolutb.org.tr/media/ziraat/Nohut-ve-Tarimi.pdf. Adresinden alınd1, Erişim Tarihi: 13.11.2018

Arıkan, M., 2011._Adana İlinde Kolza Üretiminde Enerji Kullanımı. Çukurova Üniversitesi Fen Bilimleri Enstitüsü Tarım makineları Anabilim Dalı. Yüksek Lisans Tezi.

Baran, M.F., R.Polat and O.Gökdoğan, 2016. Comparison of Energy Use Efficiency of Different Tillage Methods on The Secondary Crop Sunflower Production. Fresenius Environmental Bulletin, 25(11):4937-4943

Baran, M.F., Gökdoğan, O, 2016, Determination Of Energy Balance of Sugar Beet Production in Turkey: A Case Study For Kirklareli Province, Springer Energy Efficiency (2015) 9: (2) 487-494, ISSN: 1570-6478; DOI 10.1007/s12053-015-9375-x

Baran, M. F, Gökdoğan. 2017 Energy Balance in Production of Chickpea in Turkey: A Study Performed in Adiyaman Province, Agronomy Research, volume 15(1), 25-32, ISSN: 1406-894X

Baran, M.F. and O.Gökdoğan, 2014. Energy Input-Output Analysis of Barley Production in Thrace Region Of Turkey. AmericanEurasian J. Agric. \& Environ. Sci. 14(11):1255-1261

Barut, Z.B., C., Ertekin, H.A., Karaağaç, 2011. Tillage Effects on Energy Use for Corn Silage in Mediterranean Coastal of Turkey. Magazine of Energy. Volume 36, Issue 9, s: 5466-5475

Bayhan, Y., 2016. İkinci Ürün Ayçiçeği Üretiminde Farklı Toprak İşleme ve Doğrudan Ekim Yöntemlerinin Enerji Kullanım Etkinliğinin Karşılaştırılması. Tekirdă̆ Ziraat Fakültesi Dergisi ,2016: 13 (02) 102

BioGrace-II, 2015. Harmonised Calculations of Biofuel Greenhouse Gas Emissions inEurope. BioGrace, Utrecht, The Netherlands. http://www.biograce.net.

Clark, S., Khoshnevisan, B., Sefeedpari, P., 2016. Energy efficiency and greenhouse gas emissions during transition to organic and reduced-input practices: Student farm case study. Ecological Engineering, 88; 186-194.

Çelen, İ.H. 2016, Tarımsal Uygulamalarda Enerji Kullanımı Üzerine Bir Değerlendirme, Electronic Journal of Vocational Colleges- S: 18-29 Aralık 2016

Davoodi, M. J. Ş., Housyar, E. 2009. Energy Consumption of Canola and Sunflower Production İn Iran. American-Eurasian J. Agric. \& Environ. Sci., 6(4): 381-384. ISSN 1818-6769, IDOSI Publications.

Demir, O, 2018. A case Study of Energy Balance and Energy Economics Analysis of Irrigated Wheat Production in Turkey Fresenius Environmental Bulletin, 27(5A):3759-3765

Elhami, B., Akram, A., Khanali, M., 2016. Optimization of energy consumption and environmental impacts of chickpea production using data envelopment analysis (DEA) and multi objective genetic algorithm (MOGA) approaches. Information Processing in Agriculture, 3 (3); 190-205.

Eren, Ö., 2011. Çukurova Bölgesinde Tatlı Sorgum (Sorghum Bıcolor (L.) Moench) Üretiminde Yaşam Döngüsü Enerji ve Çevresel Etki Analizi. Çukurova Üniversitesi Fen Bilimleri Enstitüsü Tarım Makinaları Anabilim Dalı Doktora Tezi. Adana 2011.

Eren, Ö., Gökdoğan, O., Baran, M.F., 2019. Determination of Greenhouse Gas Emissions (GHG) in the Production of Different Plants in Turkey. Fresenius Environmental Bulletin, 28 (2):

Farrell, A.E., Plevin, R.J., Turner, B.T., Jones, A.D., O’hare, M., Kammen, D.M., 2006. Ethanol Can Contribute to Energy and Environmental Goals. Science, 311:506-508.

Ferrago, D. O., 2003. Energy Cost/Use in Pesticide Production. Encyclopedia of Pest Management.

Gökdoğan,O, 2016, Determination of İnput-Output Energy and Economic Analysis of Lavender Production in Turkey, Int $J$ Agric \& Biol Eng, IJABE, May, 2016 9(3): 154-161 
Güler, İ, E., 2011. Erzurum Yöresinde Nohut Tarımının Mekanizasyon Sorunları ve Çözüm Önerileri Iğdır Üni. Fen Bilimleri Enst. Der. / Ĭğdır Univ. J. Inst. Sci. \& Tech. 1(4): 91-98, 2011.

Houshyar, E., Dalgaard, T., Tarazgar, M.H., Jorgensen, U., 2015. Energy input for tomato production what economy says, and what is good for the environment. Journal of Cleaner Production, 89; 99-109.

Hughes, D.J., West, J.S., Atkins, S.D., Gladders, P., Jeger, M.J., Fitt, B.D., 2011. Effects of disease control by fungicides on greenhouse gas emissions by U.K. arable crop production. Pest Manag Sci, 67; 1082-1092.

Khoshnevisan, B., Shariati, H. M., Rafiee, S., Mousazadeh, H., 2014. Comparison of energy consumption and GHG emissions of open field and greenhouse strawberry production. Renewable and Sustainable Energy Reviews, 29; 316-324.

Kılıç, T., 1997. Türkiye'de Yemeklik Baklagil Üretim Tüketim Ticaret ve Dışsatım Pazarlama Yapısı. Ç.Ü., Fen Bilimleri Enstitüsü, Tarım Ekonomisi ABD., Basılmamış Y. Lisans Tezi, Adana

Koçtürk, O.M. and S.Engindeniz, 2009. Energy and Cost Analysis of Sultana Grape Growing: A case study of Manisa, west Turkey. African Journal of Agricultural Research, 4(10):938-943

Kökten, K, Kaplan, M. Gökdoğan, Baran, M.F., 2018 Determination of Energy Use Efficiency of Maize (Zea mays intendata)production in Turkey, Feb - Fresenıus Environmental Bulletın, ISSN 1018-4619, Volume 27-No:3/2018, pages: 1973-1978

Küçükalbay, M., Akbolat, D., 2015. Nohut Yetiştiriciliğinde Farklı Toprak İşleme ve Ekim Yöntemlerinin İncelenmesi. Süleyman Demirel Üniversitesi Ziraat Fakültesi Dergisi 10 (2):1-10, 2015 ISSN 1304-9984, Araştırma Makalesi

Mandal K G, Saha K P, Ghosh P K, Hati K M, Bandyopadhyay K K (2002) Bioenergy and Economic Analysis of Soybean Based Crop Production Systems in Central India. Biomass and Bioenergy, 23: 337-345

Marakoğlu, T., O.Özbek and K. Çarman. 2010. Nohut Üretiminde Farklı Toprak Işleme Sistemlerinin Enerji Bilançosu. Tarım Makinaları Bilimi Dergisi, 6(4):229-235

Maraseni, T.N., Cockfield, G., Maroulis, J., Chen, G., 2010. An assessment of greenhouse gas emissions from the Australian vegetables industry. Journal of Environmental Science and Health, Part B, 45:6, 578-588.

Mart, D., 2018. Yemeklik Tane Baklagillerin Önemi Ve Yetiştiriciliği. T.C. Gıda, Tarım ve Hayvancılık Bakanlığı Tarımsal Araştırmalar Ve Politikalar Genel Müdürlüğü Yemeklik Tane Baklagiller Çalıştayı. S:108-120. Adana

MGM, 2018. https://www.mgm.gov.tr/veridegerlendirme/il-ve-ilceler-istatistik.aspx?m=Adana, Adresinden alınd1 11.07.2018

Mohammadi, A., Rafiee, S., Jafari, A., Keyhani, A., Mousavi-Avval, S. H., Nonhebel, S., 2014. Energy use efficiency and greenhouse gas emissions of farming systems in north Iran. Renewable and Sustainable Energy Reviews, 30; 724-733.

Mousavi-Avval, S., H., Rafiee, S., Jafari, A., Mohammadi, A., 2011. Energy Flow Modeling and Sensitivity Analysis of Inputs For Canola Production In İran. Journal of Cleaner Production,19(2011)-1464-1470, (www.elsevier.com/locate/biombioe, USA).

Nguyen, T.L.T., Hermansen, J.E., 2012. System expansion for handling co-products in LCA of sugar cane bio-energy systems: GHG consequences of using molasses for ethanol production. Applied Energy, 89; 254-261.

Öztürk, H. H., 2011. Bitkisel Üretimde Enerji Yönetimi. Hasad yayıncılık. 2011.

Öztürk H.H., Küçükerdem K. H., 2016. Ayçiçeği Üretiminde Enerji Kullanımı Imcofe'16: Internatıonal Multıdıscıplınary Congree of Eurasia $823-832$

Pishgar-Komleh, S.H., Sefeedpari, P., Ghahderijani, M., 2012. Exploring energy consumption and CO [sub 2] emission of cotton production in Iran. Journal of Renewable and Sustainable Energy, 4: 033114-033115.

Sabah, M., 2010. Söke Ovasında İkinci Ürün Yağlık Ayçiçeği Üretiminde Enerji Kullanımı. Çukurova Üniversitesi Fen Bilimleri Enstitüsü Tarım Makinaları Anabilim Dalı. Yüksek Lisans Tezi. Adana.

Spugnoli, P., Dainelli, R., D'Avino, L., Mazzoncini, M, Lazzer, L., 2012. Sustainability of sunflower cultivation for biodiesel production in Tuscany within the EU Renewable Energy Directive. Biosystems Engineering, 112 (1); 49-55. 


\section{Avrupa Bilim ve Teknoloji Dergisi}

Strapatsa AV, Nanos GD, Tsatsarelis CA (2006) Energy Flow for Integrated Apple production in Greece. Agric Ecosyst Environ 116:176-180

TÜIK, 2018. https://biruni.tuik.gov.tr/medas/?kn=92\&locale=tr Adresinden alındı. Erişim Tarihi 22.11.2018

Unakıtan, G, Aydın, B. 2018, A Comparison Of Energy Use Efficiency And Economic Analysis of Wheat and Sunflower Production inTurkey: A case study in Thrace Region, Energy 149 (2018) 279e285

Wang, M.X., Xia, X.F., Zhang, Q.J., Liu, J.G., 2010. Life cycle assessment of a rice production system in Taihu Region, China. Int. J. Sustainable Dev. World Ecol. 17, 157-161.

Yaldız, O., Öztürk, H. H.,. Zeren, Y., Başçetinçelik, A., 1990. Türkiye Tarla Bitkileri Üretiminde Enerji Kullanımı. Akdeniz Üniversitesi Ziraat Fakültesi Dergisi 3 (1-2), 51-62. Antalya.

Yılmaz, İ, A. Özalp ve F. Aydoğmuş, 2010. Antalya İli Bodur Elma Üretiminde Enerji Kullanım Etkinliğinin Belirlenmesi: Elmalı İlçesi Örneği. Akdeniz Üniversitesi Ziraat Fakültesi Dergisi 23(2): 93-97

Yousefi, M., Khoramivafa, M., Mondani, F., 2014. Integrated evaluation of energy use, greenhouse gas emissions and global warming potential for sugar beet (Beta vulgaris) agroecosystems in Iran. Atmospheric Environment 92 (2014) 501-505. 